\title{
Architectural Hybrids for living across the Lifespan: Lessons from Dementia
}

Evangelia Chrysikou ${ }^{\mathrm{a}}$, Chariklia Tziraki ${ }^{\mathrm{b}}$, Dimitrios Buhalis ${ }^{\mathrm{c}}$

${ }^{a}$ Bartlett School of Architecture, University College London, London, UK, NW1 2BX, +44 20 7679 2000, e.chrysikou@ucl.ac.uk

b MELABEV-Community Elders Club, Research and Evaluation Department and Hebrew University of Jerusalem, Israel Gerontological Data Center, Mount Scopus 9190501, tziraki@gmail.com

${ }^{\mathrm{c}}$ Department of Tourism and Hospitality, Faculty of Management, Bournemouth University, UK, BH12 5BB, +44 1202 961517, dbuhalis@bournemouth.ac.uk

Correspondence details: Dr Evangelia Chrysikou (e.chrysikou@ucl.ac.uk)

\section{Acknowledgement}

"This work was supported by the European Union's Horizon 2020 under Grant No 658244" 


\begin{abstract}
Maintaining health, independence and autonomy are associated with a longer and meaningful lifespan. Architecture and the built environment are critical for the quality of life across the lifespan, and especially at the late stages of life when people are less mobile and often suffer from form of disability. The theory of salutogenesis, focusing on human health and well-being, rather than the disease itself (pathogenesis) provides evidence that space and built environment contribute to an increased sense of wellbeing across the aging life span. This framework has influenced the medical architecture sector as facilities are designed to facilitate the wellbeing of users. However, most aspects of built environment, including the domain of urban developments retain mostly segregated functions. Learning from the hospitality sectors, where traditionally hotels and hospitality facilities have been designed to offer pleasurable experiences, can be of benefit. Increasingly healthcare facilities aim to look and feel like hotels, that provide specialist (health) services in order to improve user experience and to make it as pleasurable as possible. This does not eliminate the conceptual and usage gaps between hospitality and health facilities, but supports cross fertilization of best practice from both domains. This paper explores the possibilities of more synergistic domains for the creation of urban developments, health care provision facilities and hospitality industry. Appropriate services and quality of life across the lifespan is the ultimate objective and the physical environment is critical in that provision. It is using the architectural typology interpretation of the first dementia village as a case study to explore how to create hybrids between healthcare and hospitality. Bringing lessons from both domains can contribute to the silver economy while providing the aging population with enhanced built environments. Aging population as well as all the stakeholders in this ecosystem can benefit from exploring the synergies.
\end{abstract}

Keywords

Dementia, architecture, hospitality, dementia village, ageing population, silver economy

\title{
Introduction
}

In Europe, the 15-20 year difference between life expectancy and healthy life years is challenging policy makers and the society globally. This led to the European Commission setting up a target of adding two more healthy life years by 2020 (Lagiewka 2012). For that purpose, the Health and Digital Directorate of the European Commission has created a joined framework, the European Innovation Partnership (EIP) on Active and Healthy Ageing (AHA), known as EIP on AHA (EIP on AHA 2016). It aims to improve the quality of life for people across the lifespan and to address barriers that might prevent this target from being reached (European Commission 2016). The framework promotes synergies, bringing together disciplines right from the conceptualization of a project. Part of its actions has been the 2016 Call for Commitments, a project aiming at bringing together stakeholders across industries, i.e, finance, built environment, healthcare provision, tourism etc. The aim is to include the entire decision making spectrum, i.e., from end-users to governance and across geographical regions. Due to the experimental, innovative and bottom up nature it displays a higher degree of flexibility and freedom compared to most European Actions. This action bears strong similarities with the unconventional, multisector and multi-disciplinary social innovation initiated by the Japanese Government to address ageing society and healthcare (Okada et al 2013). Most government and international organisations start realizing the importance wellbeing across the prolonged lifespan, as well as 
the financial implications of the ageing population in pensions, healthcare and social care and urgently seek cost effective, appropriate solutions to support citizens.

Technology alone or healthcare alone cannot address AHA, despite the fact that the majority of R\&D and resources tend to concentrate on these fields. This was reiterated in the EIP on AHA summit in Brussels by the CEO Agfa Healthcare, Luc Thijs (2016) who argued that the environment that healthcare and technology operate is absolutely key to the AHA. The majority of people across the lifespan are first and foremost citizens, rather than patients in a hospital environment. They have a varying array of needs and abilities and they require a variety of adjustments and options in their environments. Services, both hard (such as Buildings, Maintenance, Heating, Air Conditioning, Lighting, Plumbing, Safety Systems) and soft (such as Health and Social Care, Catering, Entertainment, Culture and Art, Cleaning, Waste Management, Security) need to be integration on their approach from the planning stages all the way to management and operations to meet the expectations and needs of the different stakeholders as well as achieve better quality of service, synergies and operational efficiency. In line to this fact, the paper aims to explore how architecture can support ageing. To learn from best practice we identify lessons learned from best practice in Dementia Specialised Care as well as from best hospitality practice and experiences in hospitality settings. People often associate hospitality with pleasure, entertainment, warmth and sense of wellbeing as well as with a friendly, welcoming, innovative kind, and social environment which is often better than home and that is why they choose to relocate temporarily and spend time and money in this adopted environment. Choice and commitment demonstrates that they have a strong preference and desire to live in these places and benefit from their services. As a result the paper therefore proposes a model/framework for architecture to improve living across the lifespan.

\section{Learning from medical architecture and hospitality}

In order to achieve an integrated perspective on designing for across the lifespan, literature needs to include all major sectors, including design for neurodiversity, multimorbidities and frailty on one hand and well-wellbeing and social inclusion on the other, with an emphasis on hospitality. as it is a sector very much related to physical and mental restauration and covers an extensive range of activities. Hospitality services include a range of different aspects including living and rest (Sleep) spaces, eating and drinking food and drink preparation (kitchens) and service facilities (bars, pubs, cantins, restaurants, etc) as well as entertainment and socialization spaces such as a theatres, cinemas, as well as more specialized facilities such as Conferences and Meetings spaces or Spa-wellness-fitness facilities (Brotherton,1999, Jones and Lockwood, 1998, Neuhofer, Buhalis and Ladkin, 2015)

Employing design for supporting the health and wellbeing of patients is an established practice in hospital architecture since the 80's (Verderber 1986, Zeisel et al 2003, Shepley 2009). Key findings, especially on the use of daylight (Joarder et al 2003) views and nature (Ulrich et al 1991, Alvarsson et al 2010, Verderber 1986) effects of art (Nanda 2012), may prove useful in other forms of the built environment, such as hospitality, malls, social housing among other. However, over-generalisations from one context to another might prove over-simplistic, as research on the transfer of normalization from autism to acute mental health has indicated that such loans should be subject to critical review and further research before any application (Chrysikou 2014). Yet, a growing body of knowledge on design for vulnerable populations, on 
perception and neuroscience, combined with the increased tendency for people to receive care in the community and closer to home, indicates that the impact of the field could be much larger than just hospital and healthcare facilities design.

There are several parallel, mainly overlapping, theoretical approaches that focus on the research and implementation of evidence-based Eco-psychosocial interventions aiming to support the mechanisms that generate health or help combat disease. These are known as medical or therapeutic architecture, generative space or salutogenic design; terms that initially derived from the theory of Salutogenesis originated the field of Medical Sociology (Antonovsky 1979, Antonovsky 1987). This theory refers to the possible impact of environmental interventions to increase wellbeing and sense of social coherence. Salutogenesis does not claim to substitute medical intervention or treatment. On the contrary, its aim is to support staff, carers and patients by decreasing the amount of effort needed to overcome stressful situations as well as by providing complimentary support. This eco-psychosocial support is more important in conditions that Christensen \& Hwang (2009) describe as having low diagnostic and interventional accuracy, such as the umbrella of mental health, including Alzheimer's (Zeisel 2010). In the case of Dementia, Zeisel proposed the manipulation of the physical environment through elements of positive and negative distraction as a way to promote cognition. The importance of the physical environment for healthy ageing, its spatial configuration and quality of construction in the context of the urban scale, is well documented by Marmot (The Marmot Review 2010, Marmot 2015). Design that promotes physical exercise, social exchange and autonomy has been also included among emerging innovations under the term "intangible technologies providing help with everyday living" by research on innovation and services for ageing (Djellal \& Gallouj 2006).

Moreover, work conducted on other forms of the built environment, could shed more light on the way we design for healthcare. For example, the work of space syntax on social housing (Hanson 2001, Hillier \& Hanson 1998) and social housing and housing provision for dementia (Bligh 2016), as well as housing design and active lifestyle (Brookfield et al 2015) and care homes (Coomans et al 2016, Croucher 2008) demonstrate a variety of possibilities, where evidence based design could affect social cohesion and quality of life for vulnerable groups in general.

In addition to the aforementioned architectural research streams, an area that human centred policy and design should take into account is that of accessibility. Its main emphasis has been on enabling people with mobility, vision and hearing impairments to fully function in their environment. Unfortunately, brain related difficulties have not been equally addressed. Especially universal design means and devices present limitations to accommodate the needs of several vulnerable groups and in particular those least represented, as research on fall prevention and AHA indicates (Herman 2016, Gutman 2016). This could be attributed to prevailing compartmentalized, as opposed to eco-psychosocial, ways of health and social care delivery. This lack of integration has cast a strong influence on facilities planning.

However, lately an increasing understanding of the value of multidisciplinary and user-inclusive approaches starts to penetrate architectural research and education and raises awareness on the need for inclusive spaces for people across the lifespan (Chrysikou et al 2016). Additionally, the travel and leisure industry has started identifing opportunities deriving from catering for the 
needs of people at early stages of Dementia and their partners (Bournemouth University 2013). Yet, the service provision is still at its infancy (Visit England 2016). The research conducted on the tourism sector focuses primarily on soft management interventions such as training and dementia friendly services (Page et al 2013, Innes et al 2016, Hartwell et al 2016) or the importance of real interaction experience in services for people across the lifespan (Zichun Chu \& Juchun Chu 2013). However, research has not yet incorporated built environment interventions as part of cognitive function requirements. As a better understanding of conditions, such as Alzheimer's, or situations, such as side effects of medication, affecting the brain is emerging, there is a great opportunity to build new facilities that improve interaction with users. Work on way-finding for older adults in airports supports legible layout and design as a more realistic solution for the most vulnerable travelers compared to technological devices (Bosch \& Gharaveis, 2016).

Regarding hospitality settings and their influence to wellbeing, until recently there has been limited exchange of information between the health and hospitality sectors of non-residential architecture. Yet, this appears to change. Hospitality since late 90s proved an important influence of healthcare architecture, especially in the UK. The functionalistic, capital-expenditure friendly Nucleus hospital typology (Francis et al 1999), started to become challenged by the salutogenic theory. As a result, the patient friendly perspective of the Plane Tree hospital model gave way to the consumer oriented approaches in hospital design of the US private healthcare sector (Malkin 2002, Frampton et al 2008). This started introducing "hotel-like" aesthetics and design solutions (figure 1), such as the single en-suite patient bedroom or the use of carpet and art or even pianos in public hospital design (figure 2). In addition, residential references, driven by the homelike approach of normalization theory for developmental disabilities are also influencing design. This customer-oriented approach is expected to have an increased influence on healthcare facilities provision in the future (Huisman et al 2012). Yet, hotels avoid describing their space as promoting physical restauration or present hospital-like, clinical aesthetics.

Demographic evidence and analysis of tourism trends imply a future increase in the number of people with health problems who travel (Eichhorn, Miller, Michopoulou, Buhalis, 2008). Similarly, the role of senior citizens in the tourism industry is expected to be higher than the overall expected increase (Grimm et al 2009). Health oriented tourism is expected to benefit from this demographic shift. Moreover, evidence from the field of social tourism identifies benefits regarding the subjective wellbeing, the social engagement and the self esteem of people across the lifespan when travelling (Morgan et al 2015). As the field of health and accessible tourism grows, hotels and hospitality facilities are motivated to accommodate guests with special needs (Darcy \& Pegg, S. 2011, Buhalis and Michopoulou, 2013). Healthcare design and service provision may support hospitality organisations to serve a much wider spectrum of guests.

[Insert Figure 1 here][Insert Figure 2 here]

Although there might be some guidance for travelling and ageing for dementia, this primarily concentrates on the transportation rather than the accommodation. For dementia in particular, guidelines on hotel choices involve very generic mentions of the importance of layout, simple practical advice on the toilet door being open at en-suite rooms and temporary signage used as a navigation means at rented accommodation (Alzheimer's Society 2016). Additionally, research on domestic environments and ageing in place demonstrates that design solutions for ageing such 
as single level homes, do not suffice when cognitive deterioration is involved and that special design and technological considerations need to be employed (Hoof et al 2013).

In line with the synergetic spirit of EIP on AHA, this paper emerged from the issues identified through the collaborative, multidisciplinary activities generated by an approved Commitment running from 26/09/2016 until 01/08/2019. The Commitment falls into the broader area of 'Innovation Age-Friendly Buildings Cities \& Environments'. The Commitment focuses on the interaction of health and wellbeing with the physical environment; including its uses of health and hospitality. It primarily aims to improve quality of life for people across the lifespan, recognizing that elderly people tend to require more health and social care services and have more disabilities. It brings together three main axes related to wellbeing and AHA, namely: the interface between health, tourism and the built environment. It also maintains the cross boarder collaboration principles and support key European research attributes (Alzheimer's research UK blog 2016).

\section{Methodology}

This paper builds on the above actions and evidence based research. The methodology involves literature review, participant observation, architectural auditing from a salutogenic perspective and space syntax analysis. The triangulation of all methodologies detects a) therapeutic elements and b) spatial hierarchies and host vs inhabitant relations at the locus of the research.

It uses as a case study the first and most internationally acknowledged village-type accommodation for dementia, De Hogeweyk a gated model village in Weesp, Netherlands. (CNN 2013, BBC News 2012, The Guardian 2012). The Hogewey complex simulates a real village with twenty-three houses that accommodate six people, as well as a village with a town square, supermarket, hairdressing salon, theatre, clubroom, and café-restaurant. Residents have their own large bedroom and share the living room, kitchen and dining room with other residents. Each house reflects the style and background of the people who live in that house. There are no locks on the doors and residents are free to walk or cycle around within the village. A range of plain-clothed medical professionals provide care, whilst most of the everyday chores are taken by residents that are doing their shopping at the supermarket and cooking as normal. A total of 250 carers, doctors and nurses work around the clock to provide the 152 residents the necessary 24-hour care. Evidence demonstrates that Hogewey residents with dementia are more active and require less medication.

The researchers started the fieldwork in May 2016 after acquiring the architectural plans of the village and conducting a detailed literature review. Then they visited the village in July 2016, gathering photographic records of all street and public areas network and conducted participant observation, in two consecutive days, including a Sunday where some of its public amenities such as the supermarket were closed but when family members could visit. Private areas, i.e., individual homes were not accessed to disrupt the life of the village as little as possible; yet semi-private areas such as the courtyards outside of the houses had been accessed. With regards the intimate areas, such as toilets, researchers accessed only those inside the public areas and not 
inside the private ones, i.e. in the houses. Extensive notes were taken throughout the visit whilst photographic evidence was collected for further analysis.

The Dementia village was chosen as a case study for its status as one of most innovative built environment and service provision interventions for old age. It is acknowledged though that the village is a specialized type of facility for dementia sufferers and most people do not require similar levels of care. However, it makes an excellent case to look at, as designing for people with dementia in mind can create inclusive environments, accessible to most of the people across their lifespan. Unfortunately dementia will affect a large proportion of the global population as Baby-boomers approach old age.Dementia is a condition that affects both the physiology and the perception considerably and therefore it affects the general population at large. Dementia not only affects the quality of life of the sufferer but of the entire family and especially the partner of the person. Therefore it has immediate implications to the quality of life of both the patient and their relatives, especially the ones they cohabit. .

\section{Empowering Architecture and Space for usage from all}

The Hogewey Dementia Village derived from the replacement of a care home and was aimed to introduce a non-institutional, patient-friendly approach to the concept of care home. As the name demonstrates, it was conceptualized as a village, generating a brand name for dementia accommodation that has been since transferred to other parts in the world, including the UK and Italy. According to one of the founders it aimed to recreate the concept of neighborhood (CNN 2013). In fact, salutogenesis could be considered being the key principle of this first dementia village. One the founders described a normative care home as a place that "thank god we never got to be in a nursing home". From this stemmed their motivation to demolish the existing care home and replace it by a village that will enable residents to live as normal life as possible (CNN 2013). Under that influence, they introduced normalization theory principles aiming to improve patients' quality of life in a homelike environment. Normalisation, claimed that care for autism environments, bearing as many references to ordinary life as possible, as opposed to clinical or institutional environments, would benefit the children with autism. Yet, the bounders of its applicability have been stretched and it has over the time influenced to one degree or the other most longer-term care provision (Peace 1998), including care homes (Steenwinkel et al 2016). In the case of the Hogewey Dementia Village, normalisation has been applied in most services. For example staff does not wear uniforms or residents can "shop" in the market and plan their meals. The master plan of the village has many references to an urban complex, including a high street and in design details such as single room accommodation. There is a range of aspects that can be transferable and can support the design of inclusive facilities that can improve the quality of life for people across the lifespan and address a number of disabilities often associated with ageing.

The village develops inwards of a continuous fence-like building, which doubles as a clear boundary between the village and the outskirts of actual village of Weesp (figure 3), where Hogewey sits geographically. This provides balance between privacy and anti-ligature and is in agreement between the initial objectives of De Hogeweyk: a non-institutional, providing qualities such as privacy, interpretation of a care home, providing safety and security. Also, under the umbrella of salutogenesis, the concept used spatial elements as therapeutic means. For example, the village concept is used from the normalization stream of the salutogenic umbrella, 
as opposed to a clinical model. Users are treated primarily as residents in a controlled environment that supports everyday function as well as medical requirements, rather than patients. In this village they incorporated thematic aesthetics and employed perception clues through art, which derives from the salutogenic negative/positive distraction design principles developed by Zeisel (2010).

\section{[Insert Figure 3 here]}

Architectural morphology-wise Hogewey chrematistics include the following:

- Single entry point accessibility to control movement; as opposed to a multiple network of possible entry and exit points, that is even the case in medieval castle-type villages, which tend to have a more controlled entry point network compared to most urban structures.

- Fixed structure that lacks the organic growth and flexibility of a village; as villages (as opposed to urban developments) are normally built piece by piece over the years according to individual needs, family growth etc.

- Inhabitants are the guests, rather than the hosts. Despite the fact that residents remain at the village for the rest of their lifespan, they are located in the most spatially segregated parts and the host (staff members) controls the most integrated parts.

- Zoning is applied according to the background and lifestyle of the residents. Hogeweyk offers residence in seven different lifestyles provided: Stedelijk, for those used to living in an urban city area; Goois, with an aristocratic Dutch feel; Ambachtelijk used to working as trades people or craftsmen/women; Indisch for those with an association with Indonesia and the former Dutch East Indies; Huiselijk for homemakers; Cultureel for those brought up with theatre and cinema; and Christelijk for those with a central religious aspect to life, whether Christian or another religion. Residence is organized according to the seven distinct themes, which have been preselected by the planning team, rather than a more flexible, user-led approach.

- A core and cluster model of a centralized multi-functional is utilized for the village to simulate a public core with satellite accommodation clusters, that is a common form of residential architecture typologies.

- the house residents do not share family bonds, in which case the houses would be smaller to accommodate the immediate family only. Instead they follow the norms of strangers' house-sharing, similar to student accommodation.

These traits indicate a pre-programmed, rather structured typology In particular the controlled access, the predetermined form and capacity, and the thematic classification of the accommodation provision are clear demonstrations of this structural approach. The power of the host, who does not stay on the premises $24 / \mathrm{h}$ even if the facility is staffed around the clock, over the inhabitant, who does, illustrates that residents have little saying on how they control their lives. This structure is softened by eco-psychosocial features to increase the inhabitants' control and sense of control. For instance, De Hogeweyk demonstrates extensive use of art and visual clues to ease self-orientation (figure 4). Inclusion of elements of normality such as a high street with commercial and social functions, the use of normal staff clothing -as opposed to uniforms-, without compromising the safety or the clinical outcome provide the illusion of a normal everyday life. Via architectural traits such as the visual permeability of public spaces and lack of 
internal physical barriers of movement, it cultivates the feeling of free access. This is achieved mainly through the extensive use of glazing and the extensive use of automated doors in both horizontal and vertical communications.

[Insert Figure 4 here]

The core and cluster typology bears references to a common typology of current hospital campuses (MARU 1996), yet medical architecture is not the only area that the core and cluster model has applied. The emphasis on the areas that are accessible to residents vs support and staff areas, including offices, differs from most healthcare typologies, where medical or staff offices and support areas play a key role for spatial hierarchies. The staff-only areas in this case are visually obscured, even though they are located close to the entrance and lack direct connectivity to the patient areas. This is to reinforce the normality illusion of the village and transfers the message, in an ecopsychosocial manner, that staff is there to support but patients come first.

This diversification from the medical model and in combination to the use of visual clues, either through the theme houses or the almost theatrical set of the "high street", bears similarities to a more hedonic type of accommodation, i.e, the holiday resort (Penner, Adams, Rutes, 2012 and Plunkett, Reid, 2013) as well as the theme park design such as Disneyland (Younger, 2016). The core and cluster model, of a central communal core and satellite accommodation clusters is a typology that fits that model too.

Indeed, Hogewey employed salutogenics but not as much normalization as the term village implies. The typology, as the researchers' auditing shows is nonresidential, contradicting the village and the normalization concepts. For instance, the separation of couples, the remote location and the age segregation that is typical of care homes and is no exception here too. Still, it does retain certain salutogenic elements. A hybrid, combining an architectural typology deriving from hospitality to a residential function is observed. Extending the application and combining the hospitality typology to the needs of the dementia patient group with the support of the salutogenic concept can support the creation on an innovative typology that includes therapeutic aspects of space.

Although the village is an experimental concept, it still carries some of the typical problems that similar, less innovative institutions, and especially care homes might present. In short, it is still on a remote location, presenting social segregation and might promote loneliness. Two urban planning issues, one architectural planning and service related and one design related that could be described as institutional remnants. The concept of the village refers to an autonomous concept of dwelling and indeed this does not contradict the planning elements that dominate the village. It was planned on the periphery of larger urban structures, presenting elements of selfgovernance and some autonomous activity. However it depends on the central more complex settlement for resources, and in particular for human resources, and more specialized services, including healthcare provision. The drawback in that case is a reduced degree of integration compared to a more central location, i.e, literally in the heart of a city, or immediately adjacent the central network of transport. This affect staff commuting to the village, increasing the chances burnout and the relatives visiting. The village is over relies, on car transportation. However, driving is overall discouraged in the country and spouses visiting might also have difficulty in using a car. This might discourage carers from visiting, increasing the isolation and 
loneliness of residents or decrease the quality of life of carers, who tend to have a lower quality of life than the average population. The separation of couples, as only the person with dementia can move in, can among others increase the hardship, loneliness, anxiety and anger of the person who remains at home (Taylor 2008, Hunt 2015). On the contrary, keeping couples together even if one of them needs care-home support starts to be recognized as a right (BBC News 2016, Human Rights Act 2015). The location of the facility and access to transportation network might increase that burden, especially since partners might be frail and with mobility or even orientation problems.

Finally, there is an age segregation element, connected mainly to service provision and policy but there are some spatial dimensions to it as well. Research on people before moving to care homes suggested that they disapproved of the age segregation that is the norm in these places, which is the case of this village as well (Croucher 2008). Policy-wise the village aims to be open to the public and in principle encourages people visiting, walking around and using facilities such as the café. Indeed, family members were visiting and one of the days there was a big birthday celebration, with a significant presence of family and friends in the bar of the village. Yet, all activity was happening immediately next to the main entrance and the rest of the streets and public places still displayed a significant degree of age segregation, as they were occupied almost exclusively by staff and residents.

The extensive use of visual clues and art as an aid for cognition was one of the clear benefits of this village. Yet, this would not continue in the intimate areas as the photograph of the restaurant toilet indicates (figure 5). That particular toilet would pose difficulties not only to an individual with dementia, but to someone that has visual difficulties or even to someone with even mild mobility problems. So, visual clues in the village support the sense of place and orientation but are not additionally employed to support tasks.

[Insert Figure 5 here]

\section{Lessons for Architectural Hybrids for living across the Lifespan}

Looking into the spatial planning of a dementia village in an effort to understand how spatial typologies and a multidisciplinary approach designed for dementia can be used for developing Architectural Hybrids for living across the Lifespan. This village-type hybrid can be considered as a new approach to the design for AHA in general, including facilities for hospitality and tourism. After performing a spatial analysis of the campus layout, the model was in fact closer to typologies already established in the hospitality industry and more specifically the resort hotels. It is important to clarify that this discussion referred to the typology in terms of spatial planning and not to the actual function, which remained a care home. Yet, this innovative spatial planning paved the ground for the revisiting of care settings and the use of space to soften institutional structures through spatial planning and design.

The analysis of the case study provides valuable lessons from architectural hybrids for improving living across the lifespan. Given the prolonged living and the need to design spaces for all aspects of architecture, including specialist forms such as medical and hospitality architecture, as well as, urban planning and design need to integrate concepts to designs to improve the quality of life for all. Hitherto, the relative lack of cross-disciplinary fluidity in aesthetics, morphology 
and typology has prevented the development of multi-purpose spaces that facilitate interaction and integration of communities. Instead of progressing in parallel, synergies and cross fertilization of concepts can facilitate design and facilitate benefits for all stakeholders.

The current demographic change, with the range of disabilities that are associated in late life strongly support that these areas of architectural research and practice, could be enriched if allowed evidence base, and in that case salutogenic principles, to penetrate through their design and even create hybrids and innovative building concepts. Enabling spaces for people across the lifespan as well as places for neurodiversity could benefit from blurring these typological boundaries as the collaborative and entrepreneurial approach of EIP on AHA is advocating. This trend is still at early stages, yet there is already visible in research by design products at concept level such as the dementia friendly supermarket till (Lab4 Living 2015) or materialized innovation, such as the case of De Hogeweyk.

This brief outline of limitations to spatial use due to design constraints could serve as an outline for opportunities for improvements and highlight lessons for inclusive design.

- Transportation and accessibility services should be considered at the planning of any facility to ensure easy access to local amenities and easy access to staff. Direct accessible public transport access to the main transport station of the catchment area will improve the accessibility of the facility and convenience for both relatives, carers and also staff members.

- Separation of couples could be avoided by simple spatial adjustments including a double bed or more complex layout changes, such as provision for bungalows. In that case the spouse-carer could among others prove more fit for care, better nourished, as malnourishment is part of the problems that especially male carers face, support staff.

- Integration of communities can also be encouraged. The core and cluster model with the core of activities close to the entrance is a model that leads to segregation closer to the edges. However, if core-related activities become dispersed spatially closer to the periphery, with a more integrated grid, the street network will serve core actions as well and help a better integration of services. Especially if these services had an added value towards the periphery, then that would promote the idea of inverse integration with the community. Best practice from theme parks and retail design and the inclusion of $\mathrm{s}$ spatial and urban planning can facilitate better integration.

- Cognitive support to individual tasks can be provided by design, art and visual clues could be extended from just assisting for way-finding. This would be even more important in tasks performed in intimate places where the person might be unescorted, such as the toilets, increasing independence and dignity.

Design areas that encourage healthy lifestyles, for health principles, including accessibility, spatial legibility and wayfinding, is also critical. This includes access to green spaces and opportunities for exercise throughout the year, healthy air quality, layouts that enable social cohesion and architectural detailing and materiality that promotes independence. These design principles, can be separated according to the grouping provided by Djellal and Gallouj (2006) to opportunities for physical exercise, socialization as well as increase of autonomy. For dementia in particular they have one more category on use of lighting and color but this could fit in the 
increase of independence and autonomy together with visual clues, patterns etc. Visual permeability is an important feature of self-orientation whilst visual obscurity could be used to support anti-ligature. It is critical to provide visual clues in all areas, especially the intimate areas that the people have less support. Urban planning and design need to address space Layouts that promote physical exercise opportunities in a comfortable and safe manner. Free access via automated means vs controlled access by human presence will support free flow and use of facilities whilst it will support better integration with society at large, reducing the feeling of segregation.

Although the research provides a plethora of interesting conclusion it is recognized that user groups, i.e., residents, staff or family members were not included in this study. A larger scale and resources projects can actively include residents, staff and carers to explore their sense of wellbeing, space and services satisfaction as well as burnout is needed. This will enable to ask for their opinion on their spatial and service provision requirements and needs. This would enhance considerably the state of the art in the design and space provision for dementia and also appreciate lessons for design for all.

From this pilot the researchers identify two research streams to explore as part of the Commitment actions. The first refers to the initial hypothesis of the village and the fitness for purpose to cater for the short or longer term needs of people across the lifespan. It could incorporate the socio-friendliness of organically developed town centres, with walking-distance facilities such as the corner-shop and social meeting points, such as the café in the central square. This concept might be worth exploring and potentially experimenting at rural areas of Europe. The second refers to taking this protected, neurodiversity informed, resort type of accommodation and adapting it for providing tourism and hospitality facilities for people with dementia. It practically means building on the existing idea of hotels for dementia but in a manner that incorporates space to the concept, together with employing specially trained staff and universal accessibility devices that the existing literature and practice suggests. This will enable the expansion of services for longer term and for the improvement of services for all.

Finally, regarding healthcare and hospitality, more synergies could promote the wellbeing and the physical and mental restoration of people. Having an example of a care home resembling a resort, how a dementia friendly resort would look like? Research on silver economy, supports that products and services enhancing autonomy is common denominator for successful enterprises, targeting both consumers across the lifespan and younger people who are carers of people across the life span or with physical or mental conditions (Kohlbacher \& Herstatt 2016) and a means to support social cohesion (Navarro-Espigares \& Hernandez Torres 2010). A hybrid environment providing travel opportunities with increased autonomy for people across the lifespan or for people at early stages of dementia and their companions could fit in that category. Learning from a multi-disciplinary approach on medical architecture and hospitality designs and taking advantage of salutogenesis, can provide a range of improvements on space and built environment planning that can increased sense of wellbeing across the aging life span. Eliminating the conceptual and usage gaps between hospitality and health facilities can develop synergies for the creation of innovative urban developments, health care provision facilities and hospitality industry that improve the quality of life across the lifespan for all stakeholders and benefit from exploring wellbeing synergies. 


\section{Acknowledgements}

Dr Chrysikou's research is funded by the European Union's Horizon 2020 research and

Innovation programme under the Marie Skłodowska - Curie Grant Agreement No 658244.

\section{Disclosure statement}

The authors declare that there is no conflict of interests regarding the publication of this paper. 


\section{References}

Alvarsson, J., Wiens, S., Nilsson, M. (2010). Stress Recovery during Exposure to Nature Sound and Environmental Noise. International Journal of Environmental Research and Public Health. 7,1036-1046. doi:10.3390/ijerph7031036

Alzheimer's Research UK blog. (2016). EU membership and Dementia research. Retrieved from http://www.dementiablog.org/eu-membership-and-dementia-research

Alzheimer's Society. (2016). Traveling and going on holiday. UK: Alzheimer's Society

and conclusions for tourism policy. A study commissioned by the Federal Ministry of Economics and Technology, Abridged version

Antonovsky, A. (1979). Health, Stress and Coping. San Francisco: Jossey-Bass

Antonovsky, A. (1987). Unraveling the Mystery of Health: How People Manage Stress and Stay Well. San Francisco: Jossey Bass Social and Behavioral Science Series

BBC News. (2012). Dementia patients in Dutch village given 'alternative reality'. Retrieved from http://www.bbc.com/news/health-20727157

BBC News. (2016). Family win fight to keep Ray and Jessie Lorrison together. Retrieved from http://www.bbc.com/news/uk-england-tyne-37837577

Bligh, J. (2016). A mainstream social housing response to dementia. Working with Older People, 20 (3), 144 - 150. DOI: 10.1108/WWOP-06-2016-0013

Bosch, S., Gharaveis, A. (2016). Flying solo: A review of the literature on wayfinding for older adults experiencing visual or cognitive decline. Applied Ergonomics, 58, 327-333. DOI: 10.1016/j.apergo.2016.07.010

Bournemouth University (2013). Accessible tourism and dementia. ScienceDaily. Retrieved from www.sciencedaily.com/releases/2013/01/130129080506.htm

Brookfield, K., Fitzsimons, C., Scott, I., Mead, G., Starr, J., Thin, N., Tinker, A., \&

Brotherton, B., (1999), Towards a definitive view of the nature of hospitality and hospitality management, International Journal of Contemporary Hospitality Management, Vol. 11 Iss: 4, pp.165 - 173

Buhalis, D, and Michopoulou, E., 2013, Information Provision for Challenging markets: the Case of the Accessibility Requiring Market in the Context of Tourism, Information \& Management, Vol 50, pp.229-239

Buzinde, C. N., Kalavar, J. M., Melubo, K. (2014). Tourism and community wellbeing: The case of the Maasai in Tanzania. Annals of Tourism Research, 44, 20-35.

Christensen, C. M., J.H., Hwang, J. (2009). The Innovator's Prescription. New York: McGrawHill

Chrysikou, E., Rabnett, R., Tziraki, C. (2016). Perspectives on the role and synergies of architecture, social and built environment in enabling active healthy ageing. Journal of Ageing Research, Active and Healthy Ageing and Independent Living 2016. Vol 2016, Article ID 6189349, 7 pages. doi:10.1155/2016/6189349

Chrysikou, E. (2014). Architecture for psychiatric environments: Environments and therapeutic spaces. Amsterdam: IOS Press

CNN. (2013). CNN's world untold stories: Dementia Village. Retrieved from https://www.youtube.com/watch?v=LwiOBlyWpko

Coomans, K., Vermeersch, W., and Heylighen, A. (2016). How do older residents experience a recently built innovative housing and care facility?. In P. Langdon, J. Lazar, A. Heylighen, and H. Dong (Eds)., Designing Around People (pp. 209-218). London: Springer 
Croucher, K. (2008). Housing Choices and Aspirations of Older People: Research from the New Horizons Programme. Communities and Local Government. London: Queen's Printer and Controller of Her Majesty's Stationery Office

Darcy, S.A. \& Pegg, S. 2011, 'Towards Strategic Intent: Perceptions of disability service provision amongst hotel accommodation managers', International Journal of Hospitality Management, vol. 30, no. 2, pp. 468-476.

Djellal, F., \& Gallouj, F. (2006). Innovation in care services for the elderly, The Service Industries Journal, 26 (03), 303-327, DOI: 10.1080/02642060600570943

DOI: $10.1080 / 02642060802337349$

DOI: org/10.1016/j.annals.2013.08.010

Eichhorn, V., Miller, G., Michopoulou, E., Buhalis, D., 2008,Enabling disabled tourists? Social Progress Through Schemes,Annals of Tourism Research, Vol.35(1), pp.189-210.

EIP on AHA (2016). European Innovation Partnership on Active and Healthy Ageing. Retrieved from https://ec.europa.eu/eip/ageing/about-the-partnership en

European Commission. (2016). Innovation Europe - A Europe 2020 Initiative. Retrieved from http://ec.europa.eu/research/innovation-union/index en.cfm?section=active-healthyageing\&pg=about

Frampton, S., Charmel, P., Planetree. (2008). Putting Patients First: Best Practices in PatientCentered Care, 2nd Edition. New York, NY: Jossey-Bass

Francis, S., Glanville, R., Noble, A., Scher, P. (1999). 50 Years of Ideas in Health care Buildings. London: The Nuffield Trust

Grey, T., Pierce, M., Cahill, S., Dyer, M. (2015). Universal Design Guidelines: Dementia Friendly Dwellings for People with Dementia, their Families and Carers. Centre for Excellence in Universal Design, National Disability Authority

Grimm, B., Heinsohn, K., Metzler, D. (2009). The impact of demographic change on tourism

Gutman, G.(2016). The Age-Friendly Cities Movement: An Evolving Concept in Health Promotion for Seniors. Proceedings of the Mobility, Mood and Place: Habitats for Happy and Healthy Ageing, 11th - 14th October 2016, Edinburgh, UK

Hanson, J. (2001). Profiling the Housing Stock for Older People: the transition from domesticity to caring (Final Report of EPSRC EQUAL Research Project MO4884). Bartlett School of Architecture UCL, London UK

Hartwell, H., Fyall, A., Willis, C., Page, S., Ladkin, A., Hemingway, A. (2016). Progress in tourism and destination wellbeing research. Current Issues in Tourism, 20, 1-63.

Herman, K. (2016). Intervention based co-design - adjusting public spaces in partnership with Councils of Seniors in Poland. Proceedings of the Mobility, Mood and Place: Habitats for Happy and Healthy Ageing, 11th - 14th October 2016, Edinburgh, UK

Hillier, B \& Hanson, J. (1988). Social Logic of Space. New York, NY: Cambridge University Press

Hoof van J., Blom,M., Post H., \& Bastein L. W. (2013). Designing a "Think-Along Dwelling" for People With Dementia: A Co-Creation Project Between Health Care and the Building Services Sector. Journal of Housing for the Elderly, (27)3, 299-332. Doi: 10.1080/02763893.2013.813424

Huisman, E.R.C.M., Moralesb, E., van Hoofa, J., Korta, H.S.M. (2012). Healing environment: A review of the impact of physical environmental factors on users. Building and Environment, $58,70-80$ 
Human Rights Act. (1998). Chapter 42, article 8: Right to respect for private and family life. London: The Stationary Office Limited

Hunt, B. (2015). The Emotional Impact on Elderly Spouses Who Placed Their Loved Ones in Long-Term (Doctoral Dissertation).Walden University, Minneapolis USA

Innes, A., Page, S., Cutler, C. (2016). Barriers to leisure participation for people with dementia and their carers: an exploratory analysis of carer and people with dementia's experiences. Dementia: the International Journal of Social Research and Practice, 15(6), 1643-1665. DOI: $10.1177 / 1471301215570346$

Joarder, A., Price, A., Mourshed, M. (2009). Systematic Study of the Therapeutic Impact of daylight associated with clinical recovery. In Kagioglou, M. ... et al, (eds.), Proceedings of PhD Workshop of HaCIRIC's International Conference 2009: Improving Healthcare Infrastructures through Innovation, HaCIRIC. 25-31, Brighton, UK

Jones, P., Lockwood., A., (1998), Operations management research in the hospitality industry, International Journal of Hospitality Management, Vol.17(2), pp.183-202

Kohlbacher, F., Herstatt, C. (2016). Silver product development: The concept of autonomy as the common denominator in innovations for older users. In S.Kwon (eds), Gerontechnology: Research, Practice and Principles in the Field of Technology and Ageing. Chapter 21, pp 429-446. New York, NY: Springer Publishing Company

Lab4 Living. (2015). D4H 24hr Design Challenge: Team 2 - SlowGo. Retrieved from http://research.shu.ac.uk/lab4living/d4h-24hr-design-challenge

Lagiewka, K.(2012). European innovation partnership on active and healthy ageing: triggers of setting the headline target of 2 additional healthy life years at birth at EU average by 2020 . Archives of Public Health -The official journal of the Belgian Public Health Association. 70(1), 23. DOI: 10.1186/0778-7367-70-23

Malkin, J. (2002). Medical and Dental Space Planning: A comprehensive guide to design, equipment and clinical procedures, $3^{\text {rd }}$ edition. New York, NY: John Wiley \& Sons

Marmot, M. (2015). The health Gap: the challenge of an unequal world. London: Bloomsbury Publishing

MARU (1996). Scanning the Spectrum of Healthcare from Hospital to home in the UK. MARU Viewpoints Seminar Programme 1996. London: South Bank University

Morgan, N., Pritchard, A., Sedgley, D. (2015). Social Tourism and Well-being in later life. Annals of Tourism Research, 52, 1-15. Doi: 10.1016/j.annals.2015.02.015

Nanda, U. (2012). Impact of visual art in patient behaviour in the emergency department waiting room. The Journal of Emergency Medicine, 43(1), 172-181. doi: 10.1016/j.jemermed.2011.06.138

Navarro-Espigares, J, L., \& Hernandez Torres, E. (2010). Ageing-related services as a key element for social cohesion, The Service Industries Journal, 30(8), 1263-1277,

Neuhofer, B., Buhalis, D., Ladkin, A., 2015, Smart technologies for personalized experiences: a case study in the hospitality domain, Electronic Markets, Vol 25(3), pp. 243-254

Okada, M., Igarashi, Y., Nomura, T., \& Tokuda, T. (2013). The Dementia Project: Innovation Driven by Social Challenges. FUJITSU Sci. Tech. J, 49(4), 448-454. Retrieved from: https://www.researchgate.net/publication/259675554_The_Dementia_Project_Innovation_Dr iven_by_Social_Challenges

Page, S., Innes, A., Cutler, C.(2013). Developing Dementia-Friendly Tourism Destinations: An Exploratory Analysis. Journal of Travel Research. Doi: 10.1177/0047287514522881 
Peace, S. (1998). K100 Understanding Health and Social Care, Block 2, People and Places. London: Open University Press

Penner, R., Adams, L., Rutes, W., (2012), Hotel Design, Planning and Development, 2nd ed W. W. Norton \& Company

Plunkett, D., Reid, O., 2013, Detail in Contemporary Hotel Design, Laurence King Publishing

Shepley, M., Baum, M., Rostenberg, B. (2009). A collaborative research project on evidencebased and eco-effective design. ARCC 2009, 6(2), 81-87. Retrieved from http://www.arccjournal.org/index.php/repository/article/viewFile/138/106

Steenwinkel Van, I., Verstraeten, E., and Heylighen, A. (2016). Adjusting an older residential care facility to contemporary dementia care visions. In P. Langdon, J. Lazar, A. Heylighen, and H. Dong (Eds), Designing Around People. Berlin: Springer

Taylor., A. (2008). Keeping older couples in care together. Retrieved from http://www.communitycare.co.uk/2008/06/24/keeping-older-couples-iLaura Capranica1ncare-together/

The Guardian. (2012). G2 Podcast: A visit to Dementia Village. Retrieved from https://www.theguardian.com/society/audio/2012/aug/27/dementia-care-hogewey-care-home

The Marmot Review. (2010). Fair societies, healthy lives. Strategic review of health inequalities in England post 2010. The Marmot Review. ISBN 978-0-9564870-0-1

Thijs, L. (2016) A European Vision and Blueprint on Digital Transformation of Health and Care. In Blueprint Digital Innovation, Morning Plenany Session (9.00 - 11.00 am). Panel discussion conducted at the European Summit on Digital Innovation on AHA 2016, on the $6^{\text {th }}$ of December 2016

Thompson Ward, C. (2015). The home as enabler of more active lifestyles among older people. Building Research \& Information, 3(1), 170-184. Doi: 10.1080/09613218.2015.1045702

Ulrich, R., Simons, R., Losito, B., Fiorito, E., Miles, M., Zelson, M. (1991). Stress recovery during exposure to natural and urban environments. Journal of Environmental Psychology, 11 (3), 201-230. doi:10.1016/S0272-4944(05)80184-7

Verderber, S. (1986). Dimensions Of person-Window Transactions in the Hospital Environment. Environment and behaviour, 18 (4), 450-466. doi: 10.1177/0013916586184002

Visit England. (2016), Accessibility Action Plan, A Strategic action plan for Tourism 2010-2020. London: British Tourist Authority (trading as VisitEngland)

Younger, D., (2016) Theme Park Design \& The Art of Themed Entertainment, David Younger

Zeisel, J. (2010). I'm still here - A breakthrough approach to understanding someone living with Alzheimer's. Great Britain: Piatkus

Zeisel, J., Silverstein, NM., Hyde, J., Levkoff, S., Lawton, MP., Holmes, W.(2003). Environmental correlates to behavioral health outcomes in Alzheimer's special care units. Gerontologist, 43 (5), 697-711. doi: 10.1093/geront/43.5.697

Zichun Chu, A., \& Juchun Chu, R. (2013). Service willingness and senior tourists: knowledge about aging, attitudes toward the elderly, and work values, The Service Industries Journal, 33(12), 1148-1164, DOI: 10.1080/02642069.2011.628659 


\section{Figures:}

- Figure 1: A gallery space at Leids Universitair Medisch Centrum in the Netherlands

- Figure 2: A public piano in Charing Cross Hospital in London, UK

- Figure 3: A general bird's-eye view of Hogewey

- Figure 4: Visual clue for better self-orientation of the users

- Figure 5: Restaurant toilet at Hogewey
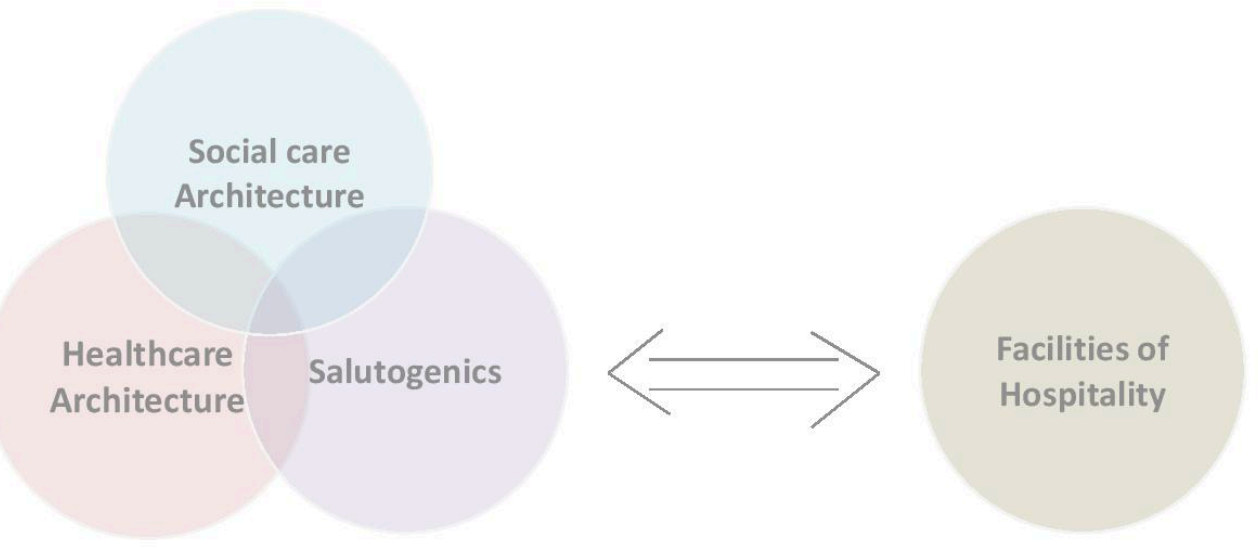